\title{
Readiness of agricultural workers to develop new competencies and change the employment model in the conditions of digitalization
}

\author{
Olga V. Zabelina ${ }^{1}$, Farida I. Mirzabalaeva ${ }^{2}$, and Larisa V. Sankova ${ }^{3}$ \\ ${ }^{1}$ All-Russian Scientific Research Institute of Labor of the Ministry of Labor and Social Protection of \\ the Russian Federation,101000, 4th Park st., 29, Moscow, Russia \\ ${ }^{2}$ Plekhanov Russian University of Economics, 117997, Stremyanny lane, 36, Moscow, Russia \\ ${ }^{3}$ Yuri Gagarin State Technical University of Saratov, 410054, Politechnicheskaya st.,77, Saratov, \\ Russia
}

\begin{abstract}
The relevance of the research is caused by the expansion of agrarian employment digital transformation. The purpose of the article is to study the readiness of agricultural workers to the digital challenges of modern times and the new model of employment. The article analyzes the expectations of agricultural workers regarding the risks of digitalization, changes in the form of employment and labor functions, change of occupation and place of residence. The critical role of the human factor in the transition to a new employment model caused by digitalization is taken as a hypothesis of the study. Underestimation of labor settings of employees lead to slowing development of agro-industrial complex. The hypothesis was tested when surveying agrarian workers. According to the survey, the level of readiness to change the employment model is more likely to be average. The most "problematic" component was readiness to learn, get a new profession. In order to increase the propensity of agricultural workers to digital employment, it is necessary to improve the system of labor management and economic incentives to develop digital competencies. The results can be used to assess the readiness and opportunity of agricultural workers to work in new conditions, manage changes in employment in the agricultural sector of the Russian economy.
\end{abstract}

\section{Introduction}

The problem of economy digitalization and its agrarian sector belongs to the system problems and requires thorough preparatory work, including the formation of human resources, new models of adequate development of this sector.

The field of agricultural employment is the most conservative in terms of internal mechanisms of human resources reproduction, and at the same time the most susceptible to transformational processes. Considering the structure and dynamics of employment in this type of economic activity, it should be noted both almost double reduction of agrarian employment since 2005 (against the background of growth or slow decline in employment in other activities) and the high interregional differentiation of the indicator. Analysis of the 
share of agricultural employment by federal districts in 2018, along with notable "leadership" of the North Caucasus Federal District in terms of share of employed in agriculture, revealed the presence of regions in each federal district with agricultural employment indicators markedly deviating from the average. In particular, these are the following regions: Tambov oblast $(23.2 \%)$ of the Central Federal District, Pskov oblast $(10.7 \%)$ of the North-Western okrug, Republic of Kalmykia (19.2\%) of the Southern okrug, Republic of Dagestan (23.3\%), Republic of Mordovia (19.8\%), Republic of Altai (17.9\%).

Despite the continuous decline in employment in the Russian agricultural sector, the problem of maintaining employment of released workers is not acute for the time being. However, in the near future there will be a task of transition to more productive technologies, formation of human resources with digital competencies of different levels.

In determining the prospects for the new agricultural employment model development, the impact effects on agricultural employment (including gender, educational, territorial and professional qualification structure) of key trends such as informatization and robotization of production, as well as the introduction of new breeding and genetics technologies should be considered. Among them, of course, informatization will be dominant. New trends and mechanisms of this sphere's development are reflected in the concept of the departmental project "Digital Agriculture" developed by the Ministry of agriculture of Russia within the framework of the segment development program up to 2024. The penetration of "smart" agriculture and livestock is gradually changing the model of employment and installation of AIC workers.

The development of scientific and production clusters in the agricultural sector, within which their employment structures will be formed, can change traditional perceptions of the employment model. Digitalization and automation of production process in agriculture creates a request for a new type of AIC personnel with new competencies (e.g. in the field of creation/use of software products, work with robotics). This, in turn, places demands on the education system and the employee's competency model. As the digital innovations most sought after in agriculture, crop and livestock management information systems can be identified, focusing on planning functions, accounting and forecasting. Typically, it's about cloud-based and customized solutions. The fuel consumption control systems, sensors for harvesters and machinery are also popular.

The next important area of concern is the imbalance of the labor market and the education system in the agrarian sphere, low level of wages, high level of manual labor, low innovative activity, labor productivity in the existing model of employment in the agricultural sector of the economy. As per the data of the Federal Service of State Statistics, out of 41 thousand employed graduates who graduated from universities specializing in "Agriculture, Forestry and Fisheries" only $48 \%$ work in received specialty. A close situation is typical only for graduates of the specialty "Sociology and Social Work" and "Management in Technical Systems". Stereotypes about the low wage level in the industry strongly influence the desire of young people to receive education in agro-industrial specialties and to work further in this field.

As the main conditions determining the format of transformations in agro-industrial complex, the studies identify the availability of infrastructure and connectivity, financial accessibility, education level (literacy, ICT field education) and institutional support [6]. In studying the factors and conditions affecting the readiness for digital transformation of employment and competencies in the agrarian sphere, various approaches to analysis can be found in the literature. According to a number of researchers, the impact of computerization has unambiguous influence on the labor market and employment; jobs at risk; the relationships between the likelihood of computerization, wages, and level of education. It has been proven that wages and education level demonstrate a strong negative relationship with the probability of computerization of the profession [12]. In the context of the study's 
topic the studies devoted to the problems of AIC digitalization and the resulting new requirements for employees $[1,2,4,6,7,8,10,14]$, problems of formation and use of the labor potential of agrarian territories [13.16] should be noted. The "digital revolution" in the agricultural sector is viewed through the prism of technology and data management problems in agriculture, as well as in the broader context of economic and political landscape - equity provision [15].

We can note the work [9] in which it is proposed to highlight such important behavioral factors (dispositional, social and cognitive factors) that allow to enrich the economic analysis of decisions taken by farmers, and to lead to more realistic and effective agro environmental policies. A large body of research is connected with the analysis of social restrictions in the AIC field, including in connection with the study of labor relations problems, social risks [3,5], etc.

The emphasis on objective factors in assessing and predicting readiness for a new employment model leads to the fact that the decision on mastering digital competencies, choosing the employment format and the mobility channel is ultimately taken by a person, not always guided by rational decisions. Agricultural workers may adhere to behavior strategies that do not demonstrate the basic tenets of a particular pattern of rational behavior.

The tasks of this study derive from the hypothesis, which can be formulated as follows: the AIC digitalization and the formation of a new employment model in it depends not only on objective, external factors, but also on subjective factors that determine the labor behavior of employees in the conditions of mastering digital competencies necessity. The latter is a consequence of a certain attitudes' combination, value orientations, which together we define as the readiness, ability and possibility of employment subjects to adapt in a new reality.

\section{Materials and methods}

The research process used data from the "Social attitudes and dispositions of the population of the Russian Federation in relation to new forms of employment: subjective assessments" Project, which was implemented on the basis of the Resource Center for Sociological and Internet Research of St. Petersburg State University using a computer system for conducting telephone surveys / CATI (Computer Assisted Telephone Interviewing). *

The target group of the study - citizens of the Russian Federation in the age range of 1859 years, engaged in income-generating employment. The representative sample for the allRussian telephone survey was 1,634. Sampling error: 5\%. Gender distribution: male 764 people $(53.2 \%)$ female -870 people $(46.8 \%)$, age distribution: $18-29$ years -494 people (30.2\%) 30-39 years - 394 people $(24.1 \%)$ 40-49 years - 368 people $(22.5 \%) 50$ 59 years -378 people $(23.1 \%)$.

Methods of work: theoretical analysis, analysis of documents, development of research design and research tools, telephone survey.

Sample: representative sample for All-Russian telephone survey with sampling error: $5 \%$ Calculation of sampling error by signs: gender, age, place of residence (types of settlements).

Project work period: June 14 - September 25, 2018, sample by type of settlements is proportional to the number of residents in regional centers, other cities, urbanized

\footnotetext{
* Scientific supervisor of the project - Doctor of Sociology., Associate Professor of the Department of Social Analysis and Mathematical Methods in Sociology of St. Petersburg State University A.V. Maltseva; scientific consultant of the project - Doctor of Economic Sciences, Professor, Head of the Laboratory of Strategic Studies of Social and Labor Relations of the Ministry of Labor of the Russian Federation O.V. Zabelina.
} 
settlements and rural areas. Distribution of selective population by type of settlements: district centers $-47.7 \%$, other cities, urbanized settlements $-37.3 \%$, village $-14.9 \%$.

The distribution of the sample population by employment area of persons with vocational education was obtained in the survey by accident (the total number of respondents is 1,442 , as this question was asked only to respondents with vocational education). In the sample of employment distribution of persons with vocational education, agriculture and agricultural science workers accounted for $4.3 \%$ (70 persons). Qualified workers in agriculture and forestry, fish farming and fisheries accounted for $2.1 \%$ (35 persons). Distribution of the sample population by economic sector: agriculture and forestry $-3.1 \%$ (50 employees).

\section{Results and discussion}

According to the McKinsey study (2017), agriculture is ranked fourth among all sectors of economy for automation possibilities. Numerous innovations in agribusiness are loosely connected, which inhibits the change of employment model in this area.

The availability of labor resources in the Russian agro-industrial complex is higher than in developed countries, but the low level of skills creates a number of serious constraints, which are factors of structural unemployment in rural areas. Agricultural labour productivity has been increasing for the past three years at an average of $4 \%$ a year. Transformation of the production model in agriculture and change in demand for food stipulates the necessity for growth in labor productivity and yield, which in turn creates a request for wide use of innovative technologies and robotization. At the same time, the reverse side of the employment restructuring in this sphere is the formation problem of new digital competencies, ensuring professional mobility and employment of released workers. In this regard, it is important to assess the opportunities and readiness of agricultural workers to adapt in the context of transition to a new development model of this economy sector.

AIC development becomes more dependent on new platform technologies of intersectoral purpose (information and communication, aerospace and biotechnology, technologies of urbanized agriculture (vertical farms, robotic greenhouses, etc.).

At the present stage, an employee of any sphere (including agrarian) must continuously expand his knowledge, improve skill in his profession, as well as be able to quickly adapt to new conditions of economic activity in order to improve its efficiency. Employees of various sectors and professional qualification groups, as well as specialists of different training profiles, see different risks of the consequences of computer technologies' widespread adoption for professional activity.

Assessment of the consequences of certain professional sphere digitalization by agricultural workers. Representatives of the agricultural sector of the economy (rural residents) are significantly behind the urban population in expectations of new skills and habits requirements $(66 \%)$, but are more concerned about job losses (49\% versus $42 \%$ ) than the urban population. Residents of villages, rural urbanized settlements assume a chance of their profession disappearing in 15 to $16 \%$ of cases.

Workers educated in agriculture and agricultural sciences are less likely to assume an increased demand for skills and skills requirements (58\%), changes in labor functions and labor content $(47 \%)$ than other educational cohorts. However, they are more prone to the expectation of their profession/speciality disappearing (13\%) and expect almost the same degree of job cuts $(46 \%)$ in terms of computerization (see Fig. 1). 


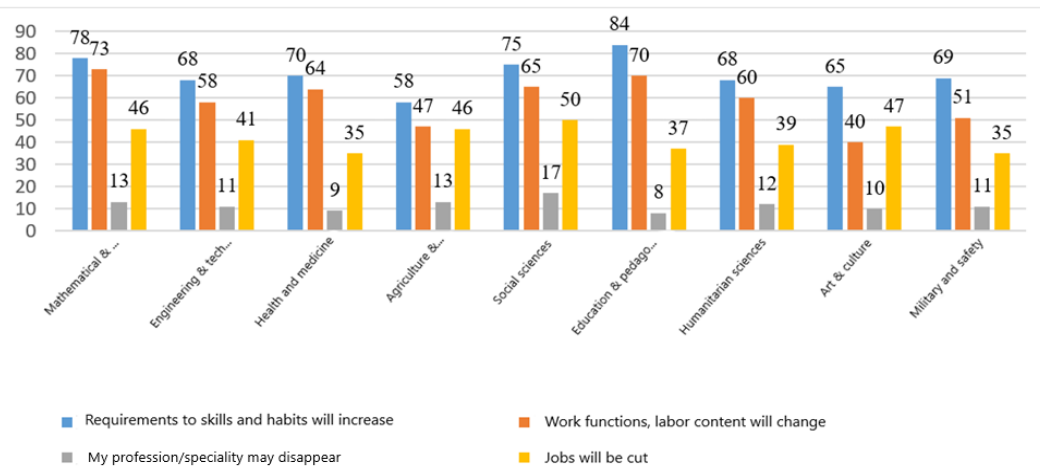

Fig. 1. The sum of "yes" and "rather yes" answers to the question about the impact of computer technologies widespread adoption on their profession in \% (distribution by field of vocational education)

Assessment of the digitalization consequences by employees of different professional and qualification groups Specialists of the highest qualification level more than other workers expect to increased requirements to skills and habits (80\%) and changes in labour functions and labour content (67\%) (see figure 2). In the group of skilled workers in agriculture, forestry, fish farming and fisheries, expectations for the impact of digitalization on the professional field are lower: $67 \%$ requirements increase in skills and habits, change of labor functions and labor content $-57 \%$, reduction of jobs $-33 \%$ of respondents of this group. Possibility of profession disappearance is estimated by the representatives of this group almost the same as skilled workers of industry, construction, transport, related occupation and specialists with average skill level (14\%), which differs significantly from the expectations of unskilled workers (27\%).

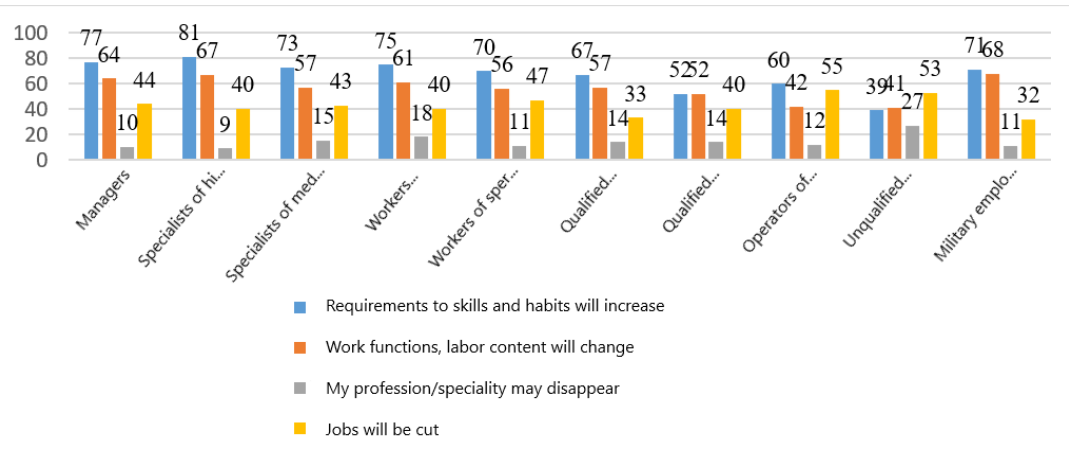

Fig. 2. The sum of "yes" and "rather yes" answers to the question about the consequences of computer technologies implementation for their profession in \% (distribution by occupancy field of respondents)

In assessing the risks of increased requirements to skills and habits, agricultural and forestry workers (as well as those employed in the industrial sector) have some "middle ground" position (64\%) compared to representatives of the education sector (80\%). At the same time, the expectations of agricultural workers to changes of labor functions and labor content $(66 \%)$ almost coincide with those of IT workers $(69 \%)$, housing and communal services $(68 \%)$, education $(66 \%)$ and trade $(64 \%)$. This trend reflects the expected changes due to the digitalization of labour processes. The disappearance of professions and job cuts 
(24\% and 68\% respectively) are expected by agricultural workers with the same extent as finance, credit, insurance and pension provision workers (28\% and 55\%) and housing and communal services $(29 \%$ and $70 \%)$. (Table 1). Thus, the widespread introduction of computer technologies in the agricultural sphere is more associated with the change of labor functions and labor content, the reduction of jobs, but not disappearance of existing profession.

Table 1. The sum of "yes" and "rather yes" answers to the question about the impact of widespread adoption of computer technologies on their profession in\% (distribution by industry / organizations of the main place of respondent's work)

\begin{tabular}{|l|c|c|c|c|}
\hline $\begin{array}{l}\text { Enterprise/organization } \\
\text { branch of the main place } \\
\text { of respondent's work }\end{array}$ & $\begin{array}{c}\text { Skills and } \\
\text { habits } \\
\text { requirements } \\
\text { will increase }\end{array}$ & $\begin{array}{c}\text { Labor } \\
\text { functions, } \\
\text { labor } \\
\text { content will } \\
\text { change }\end{array}$ & $\begin{array}{c}\text { My } \\
\text { profession/specialty } \\
\text { may disappear }\end{array}$ & $\begin{array}{c}\text { Jobs } \\
\text { will be } \\
\text { cut }\end{array}$ \\
\hline Agriculture and forestry & 64 & 66 & 24 & 68 \\
\hline Industry & 64 & 53 & 9 & 25 \\
\hline Construction & 61 & 54 & 13 & 35 \\
\hline $\begin{array}{l}\text { Transport and } \\
\text { communications }\end{array}$ & 69 & 55 & 10 & 46 \\
\hline Trade & 74 & 64 & 15 & 49 \\
\hline $\begin{array}{l}\text { Hotels, restaurants and } \\
\text { public catering }\end{array}$ & 67 & 55 & 28 & 41 \\
\hline State administration & 74 & 60 & 6 & 44 \\
\hline $\begin{array}{l}\text { Finance, credit, insurance, } \\
\text { pension provision }\end{array}$ & 43 & 62 & 29 & 21 \\
\hline IT sphere & 72 & 69 & 5 & 70 \\
\hline HCS & 69 & 68 & 10 & 29 \\
\hline Health care & 68 & 59 & 11 & 39 \\
\hline Education & 50 & 66 & 16 & 26 \\
\hline Culture and Art & 67 & 53 & & \\
\hline Consumers services & & 49 & 14 & \\
\hline
\end{tabular}

Estimation of inclination to various types of labor mobility in agrarian workers.

Digitalization of agricultural production processes inevitably affects the occupational space of employment. Employees of this sphere are ready to get a new profession (34\%) in the same scope as employees of trade (35\%), construction (34\%), service sector (33\%) and housing and communal services (34\%). The possibility of changing residence for the sake of the workplace is considered by agricultural workers in the same way as obtaining a new profession (34\%), but as a more likely scenario compared to moving to work in another industry $(28 \%)$.

The survey found that only $28 \%$ of those educated in agriculture and agricultural science consider changing their work sector (which is significantly below the same figure for persons with other educational profile: in the field of defense and security of the state, military sciences - $42 \%$ : art, culture $-38 \%$ : in the field of mathematical and natural sciences - 41\%; societal sciences $-39 \%$ : defense and security of the state, military sciences $-38 \%$.). At the same time, the readiness to get a new profession and change residence for the sake of work for agrarian specialists is one of the highest (50\%) in comparison with respondents with other professional education profile (health and medical sciences $-37 \%$, arts and culture $-31 \%$.

Contents of preferred activities of agricultural workers. According to self- 
assessment of the possibility of working only for themselves (entrepreneur, self-employed) interviewed from a group of skilled workers in agriculture and forestry, fish farming and fisheries are close to the group managers (59\% and 57\% respectively). Almost one in two respondents with agrarian education presume an option to work as an entrepreneur/selfemployed for them (47\%). According to this setup, representatives of this group are second only to persons with education in the field of mathematics and science. The revealed feature in general reflects the trend on the development of agrarian employment in the conditions of digitalization.

According to indicators of readiness for remote work (40\%), for unofficial employment without a contract (34\%), for work under a temporary labor contract $(44 \%)$ workers of agriculture and forestry occupy "middle" position in comparison to representatives of other sectors of the economy. The willingness to work remotely/distantly monotonically decreases from regional centers to rural localities.

Readiness of agrarian sector workers for training, obtaining a new profession. The survey reveals that those who have received vocational education in agricultural sciences are less willing to study or get a new profession compared to those employed in other sectors $(57.1 \%)$. This setup will hamper the possibility of professional mobility in the conditions of digital transformation of the agricultural sector of the economy and increasing risks of job losses due to labor productivity growth, introduction of innovations in the process of agricultural production.

In the analysis of groups of occupations, there are similar results: skilled workers in agriculture, forestry, fish farming and fisheries are less willing to learn, get a profession $(60 \%)$. Only unskilled workers showed lower attitude to training $(50.7 \%)$.

In the industry section, it can be observed that only about every second worker in agriculture and forestry has detected readiness for training (at their own expense or at the state expense). Among agricultural workers, the largest share (36\%) is unready for any training has been identified. The same indicators can be observed only in hotels, restaurants and public catering (31\%).

Employees of the agrarian industry showed a minimum (12\%) readiness to study at their own expense (with the fluctuation of this indicator from $21 \%$ among employees of public administration and housing and communal services up to $54 \%$, in those employed in the IT field and $52 \%$ in finance, credit, insurance and pension provision). At the same time, the indicator of readiness for training at the expense of the state or employer (44\%) is quite comparable to other industry areas.

Research shows that the key factors limiting the digitalization of agriculture today are the characteristics of rural entities, the quality of engineering and social infrastructure; level of labor organization; management technology; automation degree of management system; professional personal qualities of employees; motivation of personnel [2]. These factors lead to the fragmentary nature of digital technologies introduction, which, in turn, does not create incentives for the majority of workers in this sphere to quickly mastering digital technologies competencies, training, changing the format of employment.

\section{Conclusion}

The studies showed trends of changes in the model of labor behavior and agrarian employment in the conditions of digitalization in vocational qualification, educational, sectoral and other aspects. Training of specialists in the field of agriculture is being conducted in a sufficient amount, but a concerning factor is the low level of employment of graduates in the university's specialty in a new prospective emerging request of the labor market for specialists with developed digital skills, who are capable of providing a new development model of this problem sphere of economy in the digital age. 
The authors analyzed readiness and possibility of agricultural workers to change labor functions, training, change of employment format, development of new computer technologies, territorial mobility as integral characteristics of the emerging new model of employment in agro-industrial complex. It was noted that the greatest "problematic" component was readiness to learn, gaining a new profession, especially in comparison with the relatively high values of preparedness for entrepreneurship, self-employment. Thus, the study revealed the existence of certain modernization difficulties of the Russian agrarian sector of the economy, the existence of which is confirmed by statistical data and the findings of the researchers.

On the basis of the identified attitudes and expectations, the conclusion was made regarding the need to develop targeted training and retraining of workers with new competencies for the development of the Russian agro-industrial complex on the basis of joint efforts of the federal center, regional and local authorities and educational organizations. The digitalization of the sector will significantly change the nature of work and the requirements for workers and their skills. The request for computer literacy of agricultural workers will continue gaining relevance, which will require appropriate training and preparation. In this context, the greatest role should be played by the State, as well as in promoting the introduction of new technologies.

In the implementation of strategic goals of AIC development in Russia and its regions, reflected in national and regional projects, comprehensive measures are needed to stimulate a new model of employment in this sector, taking into account digitalization trends: modernization of the agricultural HR training system, its focus on digital skills development and continuing education; formation of a new management model at enterprises; creation of regional centers of technological competence with a set of functions for broadcasting various content technologies and digital technologies in agribusiness.

\section{References}

1. I.P. Belikova, Economics and management: problems, solutions, 11 (2018)

2. O.V. Lazko, S.V. Semchenkova, O.L. Lukasheva, Moscow Economic Journal, 4, 507$518(2018)$

3. O.VNechiporenko, M.Yu. Morekhanova, Russia: Trends and Prospects of Development, 12, 570-571 (2017)

4. S.B. Ognivtsev, Ministry of Agriculture, 2, 77-80, (2019)

5. R.R. Salakhutdinova, O.V. Nechiporenko, Sociologists of Bashkortostan on actual problems of modern society, 1, 190-195 (2016)

6. N. Trendov, S. Varas, M. Zeng, Digital technology in the service of agriculture and rural areas: background document (Food and Agriculture Organization of the United Nations, Rome, 2019)

7. V. Shustikov, Digital technology coming into agriculture. SK Skolkovo. URL: https://sk.ru/news/b/pressreleases/archive/2018/02/21/cifrovye-tehnologii-prihodyat-vselskoe-hozyaystvo.aspx

8. A. Csordás, AGRIS on-line Papers in Economics and Informatics, 12 (1), 3-13 (2020)

9. F. Dessart, J. Barreiro-Hurlé, BavelRené van, European Review of Agricultural Economics, 46(3), 417-471 (2019) https://doi.org/10.1093/erae/jbz019

10. E-Agriculture Strategy Guide. URL: http://www.fao.org/3/ai5564e.pdf

11. M. Fiszbein NBER Working Paper, 23183, (2017)

12. C.B. Frey, M.A. Osborne, The Future of Employment: How Susceptible are Jobs to Computerization? Oxford University Programme on the Impacts of Future Technology, $72(2013)$ 
13. F.I. Mirzabalaeva, O.V. Zabelina, P.R. Alieva, I.A. Shichkin, Academy of Strategic Management Journal, 16(S1), 131-148 (2017)

14. M.Murawski, M.Bick, Business Process Management Journal, 23 (3), 721-734 (2017) doi10.1108/BPMJ-06-2016-0126

15. S. Rotz, E. Duncan, M. Small, J. Botschner, R. Dara, I. Mosby, M. Reed, E.D.G. Fraser, Sociologia Ruralis, 59 (2) (2019)

16. O.V. Zabelina, F.I. Mirzabalaeva, L.V. Sankova, G.V. Yakshibaeva, European Research Studies Journal, 20 (2B), 261-282 (2017) 